\title{
Infiltração de Agentes e a Nova lei de Enfrentamento Às Organizaçóes Criminosas
}

\author{
Juliana Resende Silva de Lima
}

Polícia Federal - Brasil

$$
\approx
$$

\section{RESUMO}

O enfretamento às organizações criminosas torna-se cada vez mais desafiador, em razão do alto poderio econômico e dos caráteres transnacional e tecnológico que revestem tais organizações. Esses grupos organizados dedicam-se à prática dos mais diversos crimes, como tráfico de entorpecentes, de armas, de pessoas, contrabando, além crimes do colarinho branco e lavagem de dinheiro, dentre outros. Vê-se, ainda, a grande capacidade das organizações criminosas infiltrarem-se no Estado para, mediante corrupção, garantir que seus objetivos ilícitos sejam alcançados e que seus membros não sejam punidos pela Justiça. Diante das imensas dificuldades de enfrentamento, é importante que o Estado aprimore seus mecanismos de prevenção e repressão à criminalidade organizada, de modo a viabilizar uma vida em sociedade com mais segurança. Nesse intento, foi editada a Lei nº 12.850/2013, a qual disciplinou diversas técnicas especiais de investigação, aplicáveis aos crimes praticados por organizações criminosas, dentre as quais a infiltração de agentes. Contudo, não obstante o novo diploma legal tenha avançado na melhor disciplina do procedimento para implementar a técnica em questão, mostrou-se tímida ao autorizar, apenas, a utilização do policial como agente infiltrado em organizações criminosas. Propõe-se, em conclusão, a rediscussão do tema a fim de fomentar a alteração legislativa de modo a ampliar o espectro subjetivo de uso dessa importante técnica especial de investigação.

Palavras-Chave : organizações criminosas; transnacionalidade; repressão; Lei n ${ }^{\circ}$ 12.850/2013; infiltração de agentes;

\section{INTRODUÇÃ̃o}

O grande dilema da atualidade em matéria de política criminal pode ser sintetizado na dificuldade em se estabelecerem parâmetros para a efetiva tutela de bens jurídicos fundamentais, ponderada com a necessidade de enfrentamento da moderna criminalidade organizada. Os enormes desafios por ela impostos, decorrentes do seu caráter global, transfronteiriço e altamente tecnológico, fazem com que o Estado se veja impelido a adotar técnicas espe- 
ciais de investigação, restritivas de direitos fundamentais, com parcial sacrifício das já conquistadas liberdades pessoais.

Com efeito, os tradicionais mecanismos de investigação e repressão à prática de crimes não se mostram, há tempos, suficientes a proporcionar ao Estado, seja na fase investigatória, de iniciativa policial, seja na fase da ação penal, perante o Ministério Público e o Poder Judiciário, resultados eficazes no que tange ao esclarecimento dos fatos delituosos, identificação de autores e partícipes, modus operandi da prática criminosa, identificação e recuperação do produto do crime etc.

A agilidade e a facilidade com que o delito é praticado pelas organizações criminosas trazem imensas dificuldades à atuação dos órgãos repressores estatais. De fato, por muitas vezes, a atuação desses atores da persecução penal no esclarecimento dos fatos e punição de seus agentes torna-se defasada em comparação à capacidade de mutação e adaptação das organizações criminosas às novas tecnologias, novos modus operandi, à facilidade de substituição de integrantes, como também em relação à permeabilidade no tráfego pelas fronteiras, uma vez que os representantes dos órgãos encarregados de investigar e punir estão arredados às suas competências, limitações materiais e pessoais, restrições processuais e, acima de tudo, limites constitucionais ditados pelo respeito aos direitos fundamentais.

Estamos, assim, diante de um quadro em que o crime prospera, as organizações criminosas se multiplicam e se diversificam em forma e área de atuação, e o Estado permanece quase inoperante na sua função de prevenir e reprimir a atividade criminosa. Ao tratarmos sobre crimes praticados por organizações criminosas, não nos referimos, apenas, aos crimes violentos como tráfico de drogas, tráfico de armas e pessoas, roubos e furtos, que tanto alarmam a população; referimo-nos, igualmente, aos crimes do colarinho branco, como crimes financeiros, branqueamento, crimes de corrupção, enfim, toda sorte de delitos praticados, em geral, por pessoas integrantes de estratos elevados da sociedade e que normalmente não chegam aos olhos da grande massa, por serem consumados dentro dos escritórios e gabinetes de órgãos públicos, mas que geram tantos prejuízos ao bem-estar e à economia das nações.

Ao cunhar o termo "crimes de colarinho branco", em seu emblemático artigo "White-collar Criminality", Edwin Hardy Sutherland já previu: "O custo financeiro do crime de colarinho é provavelmente muito maior que 
o daqueles crimes tradicionalmente considerados como o "problema criminal" (SUTHERLAND, 2014).

E não é outra a realidade hoje assistida no Brasil. Não obstante o artigo em destaque tenha sido escrito no longínquo ano de 1940, permanece incrivelmente atual o seu conteúdo, especialmente se tomarmos em consideração a realidade do brasileira, na vivenciada era "Lava-Jato" como organizações criminosas com foco nesse tipo de criminalidade - corrupção, evasão de divisas, braqueamento - podem se infiltrar no Estado e produzir prejuízos financeiros e morais monumentais.

Conscientes do poder de atuação das organizações criminosas, que serão melhor esboçadas mais adiante, e das dificuldades do Estado em prevenir e reprimir as suas atividades, urge que sejam aprimoradas as técnicas de investigação voltadas à prevenção e repressão desse tipo de criminalidade. Nesse intento, o legislador editou, em 2 de agosto de 2013, a Lei no 12.850, que definiu o conceito de organização criminosa e dispôs sobre a investigação criminal, os meios de obtenção da prova, infrações penais correlatas e o procedimento criminal para sua apuração. A referida lei revogou expressamente a Lei $\mathrm{n}^{\circ} 9.034 / 95^{2}$, cujos dispositivos dispunham de forma tímida sobre os meios operacionais para a prevenção e repressão de ações praticadas por organizações criminosas, deixando em aberto a respectiva regulamentação.

A nova Lei do Crime Organizado proporcionou inovações em matéria de repressão às organizações criminosas, uma vez que regulamentou de maneira mais detalhada importantes técnicas especiais de investigação. Em seu artigo $3^{\circ}$, definiu os seguintes meios de obtenção de prova: I - colaboração premiada; II - captação ambiental de sinais eletromagnéticos, óticos ou acústicos; III - ação controlada; IV - acesso a registros de ligaçóes telefônicas e telemáticas, a dados cadastrais constantes de bancos de dados públicos ou privados e a informações eleitorais ou comerciais; $\mathrm{V}$ - intercepção de comunicações telefônicas e telemáticas, nos termos da legislação específica; VI afastamento dos sigilos financeiro, bancário e fiscal, nos termos da legislação específica; VII infiltração, por policiais, em atividade de investigação,

1 Operação policial desencadeada pela Polícia Federal para apurar crimes de corrupção, lavagem de dinheiro, evasão de divisas, dentre outros, iniciada em 2013 e ainda em curso, praticados pelos gestores da Petrobrás S.A. em conluio com os representantes das maiores empreiteiras do Brasil, objetivando o superfaturamento de obras da citada empresa de economia mista e consequente desvio dos recursos públicos.

2 O artigo 26 da Lei n. 12.850 de 2013 revogou expressamente a Lei n. 9.034 de 1995. 
na forma do art. 11; e VIII cooperação entre instituições e órgãos federais, distritais, estaduais e municipais na busca de provas e informações de interesse da investigação ou da instrução criminal.

Nos artigos seguintes, o legislador disciplinou pormenorizadamente o procedimento a ser adotado para a implementação das técnicas de investigação acima elencadas, suprindo, com isso, grave déficit legislativo da revogada Lei $n^{\circ} 9.034 / 95$. A Lei ${ }^{\circ} 12.850 / 13$, ademais, trouxe importante avanço em relação à autonomia e eficiência da investigação a cargo da autoridade policial, ultrapassando antiga controvérsia doutrinária e jurisprudencial, quando estabeleceu a sua capacidade de requisitar, independentemente de autorização judicial, os dados cadastrais dos investigados que informem a sua qualificação pessoal, filiação e endereço mantidos pela Justiça Eleitoral, empresas telefônicas, instituições financeiras, provedores de internet e administradoras de cartão de crédito ${ }^{3}$.

Contudo, no que tange ao instituto da infiltração de agentes, a novel lei acabou por restringir o âmbito de utilização de tão importante técnica investigativa, na medida em que legitimou, tão-somente, a infiltração do agente policial, excluindo a possibilidade de terceiros atuarem na colaboração com o Estado.

A práxis na Polícia Federal permitiu demonstrar que não só a infiltração de agentes de polícia tende a ser uma importante técnica de investigação, como também a infiltração de terceiros. Desse modo, pretende-se, aqui, defender que houve "timidez" por parte do legislador quanto ao instituto da infiltração de agentes, sendo mister um reestudo da questão a fim de fomentar a alteração legislativa, trazendo novamente ao arcabouço de técnicas investigativas a possibilidade de utilização de terceiros como agentes infiltrados.

Antes, porém, de falarmos especificamente sobre a técnica da infiltração de agentes e de defender a compatibilização da legislação atual com as necessidades contemporâneas de enfrentamento da criminalidade organizada, consideramos pertinente entender, de maneira breve, o funcionamento das organizações criminosas e suas principais características. Do mesmo modo, consideramos relevante situar juridicamente o dever de proteção do Estado em relação às pessoas, garantindo-lhes a segurança em prol da paz social.

3 Artigo 15 da Lei no 12.850 de 2013. 


\title{
1. Organizaçóes Criminosas
}

Apesar do estudo mais depurado sobre as organizações criminosas remontar à segunda metade do século passado, é possível observar que desde o início do século XX, quando se estruturam de maneira mais organizada as "máfias" italianas e quando estas se expandem para os Estados Unidos da América, a doutrina passou a ter uma especial preocupação com a atuação dos grupos criminosos organizados.

A par das características próprias das "máfias" italianas, o fato é que a preocupação com esse tipo de criminalidade e seu enfrentamento tornaram-se mais patentes "quando as 'máfias' italianas e americanas passaram a ser o cerne do combate ao crime organizado, tendo em vista o seu modelo corporativo estruturado, hierarquizado, violento e com alta lucratividade" (GODOY, 2011, p. 52).

Não obstante as características altamente danosas desse novo tipo de criminalidade, ainda não havia, até pouco tempo atrás, uma real conjunção de esforços no cenário mundial, que não na própria Itália e nos Estados Unidos, a fim de entender como funcionavam essas redes estruturadas para a prática de ilícitos, bem assim para enfrentá-las.

Nesse sentido, observa BALTAZARJÚNIOR:

\begin{abstract}
Mas até a década de oitenta, o crime organizado era visto como um fenômeno circunscrito à Itália e aos Estados Unidos, eventualmente estendido ao Japão, China, Rússia e Colômbia, sendo de rara utilização no restante da Europa. É somente nas duas últimas décadas do século passado, com o fenômeno da globalização e em, especial, pela expansão do tráfico de drogas e do mercado da emigração ilegal para os paises ricos, que a criminalidade organizada passa a ser percebida como um problema mundial e não mais como um fenômeno circunscrito aos Estados Unidos, à Itália, e às telas dos cinemas. A partir daí, operou-se uma verdadeira universalização do conceito e o crime organizado passa a ser uma preocupação mundial, em um processo que culmina com a publicação da Convenção das Nações Unidas contra o Crime Organizado Transnacional (2010, p. 102/103).
\end{abstract}

Na Europa, a Itália se destacou no "combate" ao crime organizado, principalmente a partir de 1992, quando a denominada "operação Mãos Limpas" foi iniciada para "combater" a corrupção que então assolava o país, envolvendo tráfico de influência e corrupção praticada por diversos líderes 
Infiltração de agentes e a nova lei de enfrentamento às organizações criminosas

políticos, ex-chefes de governo e empresários poderosos que foram parar no banco dos réus.

No Brasil, a dificuldade de conceituação e tipificação das organizações criminosas perdurou bastante tempo, por uma questão de política legislativa. De fato, a revogada lei de combate ao crime organizado, Lei ${ }^{\circ}$ $9.034 / 95$, não trazia em seu bojo a definição jurídica do que seria considerada uma "organização criminosa", lacuna que acabava por ensejar bastante insegurança jurídica quando do enquadramento das condutas criminosas praticadas por grupos que tivessem características de organização.

\section{Conforme destaca GODOY:}

O legislador brasileiro optou por não defini-lo em Lei Ordinária. Somente com a vigência do Decreto $n^{\circ} 5.015$, de 12 de março de 2004, que promulgou a Convenção das Nações Unidas Contra o Crime Organizado, também conbecido como Convenção de Palermo, é que nosso ordenamento jurídico passou a dispor sobre uma definição de organização criminosa transnacional, conforme transcrição do art. 2. da aludida Convenção (2011, p. 61)

Apesar da falta de definição jurídica, a Lei no 9.613, de 03 de março de 1998, que dispõe sobre os crimes de "lavagem" ou ocultação de bens, direitos e valores, já trazia em sua redação original a previsão de enquadramento no delito de lavagem de capitais a conduta de ocultar ou dissimular a natureza, origem, localização, disposição, movimentação ou propriedade de bens, direitos ou valores provenientes, direta ou indiretamente, de crimes praticados por organizações criminosas ${ }^{4}$.

Da mesma maneira, a Lei no 11.343 , de 23 de agosto de 2006, que estabelece a política nacional antidrogas e define os crimes a ela associados, também já previa em seu texto a figura da organização criminosa ${ }^{5}$, embora não tenha descrito os elementos e características essenciais a delimitar tal figura.

Em 24 de julho de 2012 foi editada a Lei no 12.694, que instituiu a possibilidade de formação de um colegiado de juízes para a prática de qualquer ato processual em processos ou procedimentos que tenham por objeto

4 Na redação original do artigo $1^{\circ}$, inciso VII, da Lei $n^{\circ} 9.613 / 98$. Atualmente, com as alterações determinadas pela Lei $\mathrm{n}^{\circ} 12.683 / 2012$, o tipo penal do crime de lavagem de dinheiro configura-se com a prática de qualquer crime antecedente, não havendo mais a previsão de um rol taxativo de delitos precedentes.

5 Artigo 33, $\$ 4^{\circ}$, da Lei $n^{\circ} 11.343 / 2006$. 
crimes praticados por organizações criminosas. A referida Lei trouxe, pela primeira vez no ordenamento jurídico do Brasil, a definição legal para organizações criminosas ${ }^{6}$. Ficou conhecida como a lei do "juiz sem rosto", em referência à figura implantada na Itália no início dos anos 90 do século passado, nas investigações que envolviam a máfia, que visava preservar a identidade das autoridades judiciárias envolvidas nas investigações e julgamentos.

Aperfeiçoando a estratégia de enfrentamento do crime organizado, o legislador brasileiro resolveu, finalmente, estabelecer em lei ordinária o tipo penal de organização criminosa, prevendo as características que a definem, suprindo, assim, a antiga lacuna conceitual. Nesse sentido, a Lei ${ }^{\circ}$ 12.850/2013 trouxe no seu artigo $1^{\circ}$, parágrafo $1^{\circ}$, a seguinte definição: "Considera-se organização criminosa a associação de 4 (quatro) ou mais pessoas estruturalmente ordenada e caracterizada pela divisão de tarefas, ainda que informalmente, com objetivo de obter, direta ou indiretamente, vantagem de qualquer natureza, mediante a prática de infrações penais cujas penas máximas sejam superiores a 4 (quatro) anos, ou que sejam de caráter transnacional”.

Estabeleceram-se no Brasil, com isso, as principais características jurídico-positivas - ditas essenciais - para se enquadrar um grupo ou rede voltada à prática ilícita como organização criminosa. No artigo seguinte, a lei prevê o tipo penal consistente em promover, constituir, financiar ou integrar, pessoalmente ou por interposta pessoa, organização criminosa. E estabelece, ainda no âmbito tipológico, a pena de reclusão de 3 (três) a 8 (oito) anos, além de multa e das penas correspondentes às demais infrações, como preceito secundário.

Ficaram, então, aclarados, no quadro legal (jurídico-positivo), os elementos essenciais a caracterizar uma organização criminosa no Brasil. Nada obstante, é importante ressaltar que outras características também podem estar contidas em organizações destinadas à prática do crime. A par das características essenciais, podemos citar como elementos acessórios a estrutura em hierarquia, compartimentação de informações, conexão com o Estado (por meio da corrupção ou mesmo da infiltração de agentes do crime), uso da violência para alcançar seus intentos, exploração de mercados ilícitos ou exploração ilícita de mercados lícitos, monopólio ou cartel, controle territorial, uso de meios tecnológicos avançados, obstrução da justiça e transnacionalidade ou internacionalidade (JÚNIOR, 2010).

6 Artigo $2^{\circ}$. Para os efeitos desta Lei, considera-se organização criminosa a associação, de 3 (três) ou mais pessoas, estruturalmente ordenada e caracterizada pela divisão de tarefas, ainda que informalmente, com objetivo de obter, direta ou indiretamente, vantagem de qualquer natureza, mediante a prática de crimes cuja pena máxima seja igual ou superior a 4 (quatro) anos ou que sejam de caráter transnacional. 
Infiltração de agentes e a nova lei de enfrentamento às organizações criminosas

Quanto a esta última característica, vimos que a lei, ao definir o tipo de organização criminosa, estabeleceu que a sua existência não está condicionada à prática de crimes transnacionais ou internacionais, sendo este um elemento alternativo, mas suficiente quando não se tratar de crimes com pena máxima superior a 4 (anos).

De toda forma, é importante que se diga: com a globalização econômica e a superação de fronteiras nacionais, espalharam-se em larga escala as organizações com caráter transnacional, em virtude das facilidades de locomoção de pessoas, de deslocamento de meios, de remessa de valores, aproximação através da internet (etc).

Sobre isso, discorre RODRIGUES:

A nova criminalidade é expressão deste novo modelo de organização social para que tendem as sociedade contemporâneas, A mobilidade das pessoas e dos capitais põe em causa a lógica territorial sobre a qual elas repousam. Este movimento de fundo - um pouco retardado pela confrontação Leste-Oeste - produz agora todos os seus efeitos. As grandes construções institucionais e a concentração do poder dão lugar ao declínio dos Estados e a um mundo onde proliferam as redes $(2008$, p. 171).

Outra caraterística que permeia as organizações criminosas e que tem se mostrado cada vez mais preocupante, pela sua disseminação, é a infiltração de agentes do crime no Estado, seja por intermédio de suborno/corrupção, seja pelo ingresso através de meios legítimos (como eleição de agentes políticos, aprovação em concursos públicos, etc.). O que se tem assistido nos dias atuais é um escancaramento da capacidade de captação e de infiltração de agentes do crime organizado (ou de representantes dessas categorias) nos órgãos e empresas governamentais, onde atuam em prol dos interesses ilícitos de suas organizações.

São conhecidas situações em que a organização criminosa patrocina por longos anos os estudos de crianças e adolescentes com o objetivo de fazê-los ingressar, através de concursos públicos, em carreiras de Estado, como a Magistratura, o Ministério Público, a Polícia, dentre outras, a fim de assegurar a aplicação do direito em benefício dos membros de tais organizações destinadas aos fins ilícitos. De outro lado, há também a cooptação de políticos e financiamento de suas campanhas para que assumam cargos no Poder Executivo ou no Poder Legislativo, garantindo que a atividade legiferante e de execução das normas tenham por escopo a proteção a essas categorias criminosas. 
Objetivando situar a discussão sobre organizações criminosas no cenário nacional, considero pertinente destacar estudo feito por GODOY a respeito do crime organizado no Brasil, demonstrando que essa é uma realidade atual e latente. $\mathrm{O}$ autor enfatiza "que não se trata de mais uma questão ligada somente à repressão policial, mas sim a um grande problema sociopolítico, que atinge não só a segurança da população brasileira, como também a estabilidade econômica e o próprio Estado de Direito" (2011, p. 97).

$\mathrm{Na}$ sequência, são descritas as configurações e principais modos de atuação de duas das principais organizações criminosas existentes no Brasil, quais sejam, o Primeiro Comando da Capital, nascida nos presídios de São Paulo, e o Comando Vermelho, originária das favelas da baixada fluminense. Ambas as organizaçóes acima citadas atuam em diversas atividades ilícitas, retirando seus lucros, principalmente, do narcotráfico. Característica fundamental de ambas as organizações é o uso da violência para obtenção de seus intentos, seja para a demarcação do território frente a outros grupos criminosos, seja para causar temor na população e no Estado, como forma de demonstrar poder.

Interessante frisar que tais organizações adquiriram há tempos caráter transnacional, eis que, segundo apurado por órgãos policiais nacionais e internacionais, o Primeiro Comando da Capital - PCC e o Comando Vermelho - CV já possuem ramificações em outros países, como Colômbia, Bolívia, Paraguai e Uruguai.

Da reunião de todas as características das organizações criminosas que expusemos acima, fica a certeza: avolumam-se os desafios para o enfrentamento da criminalidade organizada, o que requer um esforço cada vez maior por parte do Estado, seja aprimorando os meios legais, seja aumentando os investimentos em meios materiais e humanos (com a melhora e contínuo investimento na formação dos policiais, por exemplo), além do necessário aparelhamento Estatal, para que se consiga obter algum resultado eficaz nessa luta.

Ainda seguindo o magistério de RODRIGUES, temos que "o crime é cada vez menos um acto e cada vez mais um conjunto de actos imperceptiveis como ilícitos e só a reconstituição do todo revela os traços de cada uma das partes" (2008, p. 175) 
Infiltração de agentes e a nova lei de enfrentamento às organizações criminosas

A forma como o Estado pode se aparelhar e se preparar, técnica e juridicamente, para a prevenção e repressão às organizações criminosas é que representa o cerne das nossas ponderações neste trabalho. Afinal, "desde um punto de vista criminológico, la especial potencialidad lesiva de la criminalidad organizada parece acreditada" (PAZ, 2008).

Tem-se, portanto, que pensar em quais políticas criminais podem ser adotadas no país e, sobretudo, quais vertentes o Direito Penal e Processual Penal devem seguir nessa seara para encontrar resultados práticos mais eficazes na repressão aos crimes praticados por organizações estruturadas, tendo sempre como balizas limitadoras os direitos fundamentais dos indivíduos estabelecidos na Constituição Federal.

Há que se buscar, sempre, uma conciliação entre a busca da verdade e o respeito aos direitos fundamentais. Só assim é que a atividade persecutória penal encontrará legitimidade, sendo certo que "dentro de los ampliados limites de la Constituición es correcta toda optimización de la verdad" (HASSEMER, 2009).

Nesse sentido, é importante enfatizar que a busca pela eficácia na repressão a essa (nova) criminalidade não pode dar azo a violações e desrespeito às garantias processuais de quem quer que esteja sendo investigado ou processado. A busca por meios mais eficazes para enfrentamento de qualquer tipo de crime, mesmo aqueles cometidos por organizações criminosas, deve estar limitada e amparada pela concepção de processo penal constitucional e humanitário, fundado no princípio da dignidade da pessoa humana, sob pena de sua completa ilegitimidade.

A fundamentação do Estado de Direito, sob o pilar da dignidade da pessoa, produz importantes efeitos jurídicos, inclusive, no âmbito do processo penal. Neste, o imputado não pode ser instrumentalizado, tratado como objeto, como se uma res fosse, mas como um sujeito de direitos, um sujeito do processo (GIACOMOLLI, 2014, p. 13).

Com efeito, o Direito Penal e o Direito Processual Penal devem representar, antes de tudo, garantias aos investigados (indiciados, denunciados e réus), consubstanciando, assim, direitos subjetivos de que não haverá julgamento por crime sem lei anterior que o defina e que o devido processo legal - "obedecendo aos trâmites procedimentais formalmente estabelecidos na constituição" (CANOTILHO, 1998) - com todos os limites à acusação e 
direitos assegurados à defesa, serão respeitados independentemente de quem seja o acusado, o que significará "a proteção alargada através da exigência de um processo equitativo” (CANOTILHO, 1998).

Entretanto, não se pode perder de vista que para o exercício, por parte dos indivíduos, de seus direitos fundamentais, inclusive de suas liberdades, faz-se mister que o Estado garanta a segurança de cada um e de todos os seus membros, sem esquecer de garantir o bem comum. Sem ela, "não é possivel o gozo dos demais direitos materiais, nem o livre desenvolvimento da personalidade humana com dignidade" (JÚNIOR, 2010, p. 187).

É nesse ponto que queremos enfatizar que tanto quanto é dever do Estado de Direito - e aqui destaco que estamos a tratar do Estado estruturado em uma Constituição democrática e em uma legislação reguladora e, sobretudo, limitadora do poder estatal - abster-se de agredir ilegalmente os direitos fundamentais pessoais, é também dever do Estado assegurar à coletividade a segurança necessária para que a vida em sociedade possa se desenvolver de maneira minimamente pacífica.

É dizer: ao eleger seus representantes no governo e no legislativo, cedendo ao Estado parcela de seu poder através do voto democrático, o cidadão espera que este mesmo Estado garanta-lhe a proteção aos seus bens jurídicos fundamentais contra agressões injustas de terceiros. Se o Estado não atende a essa expectativa de sua população, omitindo-se no enfrentamento de tais ameaças, pode-se dizer que há uma quebra da confiança depositada nesse mesmo Estado, através de seus governantes e legisladores.

\section{A esse propósito informa GUEDES VALENTE:}

A harmonização inerente ao convivio mútuo entre liberdade e segurança impele à cedência de um em detrimento do outro sem que algum perca o seu conteúdo e alcance essencial e, nunca algum deles pode ferir a área centrifuga da dignidade da pessoa humana (2016, p. 169).

Nesse sentido, a fruição do direito à liberdade, exemplo de um dos mais valorosos direitos fundamentais que o ser humano pode gozar, depende, necessariamente, da garantia do direito à segurança. Este, por sua vez, comporta duas acepções:

(a) dimensão negativa, estritamente associada ao direito à liberdade, traduzindo-se num direito subjectivo à segurança (direito de defesa 
Infiltração de agentes e a nova lei de enfrentamento às organizações criminosas

perante agressões dos poderes públicos); (b) dimensão positiva, traduzindo-se num direito positivo à proteção através dos poderes públicos contra agressóes ou ameaças de outrem (segurança da pessoa, do domicílio, dos bens)" (CANOTILHO \& MOREIRA, 2006)

Não à toa a Constituição da República Federativa do Brasil reconhece que a segurança é direito fundamental de todos os cidadãos, assegurada no caput do artigo $5^{\circ}$, ao lado do direito à vida, à liberdade, à igualdade e à propriedade. O legislador constituinte voltou a tratar do tema segurança no art. $144 \mathrm{da} \mathrm{CF}$, ao prever a segurança pública como dever do Estado e responsabilidade de todos.

E como garantir essa segurança numa era em que a criminalidade organizada se expande, se infiltra, causa temor e violência em toda a população? Esse é o desafio das novas políticas criminais e do Direito Penal material e processual, assim como dos órgãos incumbidos de executar essas políticas e de aplicar o direito. Faz-se necessário, como já dito acima, aparelhar os órgãos responsáveis pela persecução penal de instrumentos eficazes e modernos para o enfrentamento dos organismos estruturados que se dedicam à prática de ilícitos, robustecendo a legislação destinada a tal fim, sem se olvidar, por óbvio, dos direitos fundamentais, primordialmente do direito à liberdade "como fundamento, fim e limite imanente de todo o poder - quer politico, quer executivo, quer judicial" (VALENTE, 2016, p. 172) e, igualmente, dos princípios éticos que devem nortear os aplicadores do direito.

Destaco, neste ponto, as palavras de PEREIRA:

Efectivamente, parece evidente que para incrementar la eficiencia de la lucha contra la criminalidad organizada, existe una tendencia a crear instrumentos extraordinarios, entendiendo por tales aquéllos que suponen una alteración de los principios inspiradores tanto del Derecho penal material como del propio proceso justo. Todavia, muchos de ellos pueden estar justificados en las dificultades inherentes a dich a lucha, vistas las especiales en las caracteristicas de las organizaciones criminales (2012, p. 345)

Apresentada a aparente dicotomia entre as liberdades individuais e o poder-dever do Estado de garantir a segurança de todos e de cada um dos membros da comunidade, passamos a examinar os limites impostos ao Estado na relativização dos direitos fundamentais, ponderando entre a proibição de excesso na agressão a esses direitos e a contrapartida, que é a proibição de insuficiência na sua atuação, de modo a garantir que os direitos fundamentais possam ser exercidos. 


\section{Direitos Fundamentais e Dever de Proteção do ESTADO (PROIBIÇÃO DE INSUFICIÊNCIA)}

Conforme destacamos no tópico precedente, para que encontremos a medida mais equilibrada entre o respeito aos direitos fundamentais e a necessidade de robustecer as ferramentas estatais de enfrentamento às organizações criminosas precisamos efetuar a ponderação dos valores em jogo, quais sejam, as liberdades tão arduamente conquistadas pelos seres humanos e a possibilidade de restringir tais liberdades diante das ameaças à segurança da coletividade representada pela moderna criminalidade organizada.

Para encontrar essa medida, o legislador e, principalmente, o operador do direito, deve socorrer-se do consagrado princípio da proporcionalidade em sentido amplo, o qual "impone los limites materiales que deve respetar toda acción del Estado que afecte los derechos fundamentales” (PUIG, 2009).

O referido princípio evoca, à primeira vista, o seu lado vinculado à proibição de excesso, tão aclamado e necessariamente arraigado hoje no âmbito do Direito Penal material e processual, em razão dos excessos cometidos em passado não muito remoto, principalmente durante o curso de regimes totalitários. Ele representa, por certo, um dos pilares do Estado Democrático de Direito e é reiteradamente invocado para se defender a concepção garantista do Direito Penal.

Contudo, não se pode esquecer da vertente da proporcionalidade ligada à proibição de insuficiência do Estado em proteger os direitos fundamentais dos indivíduos. A noção de proporcionalidade não se esgota na categoria da proibição de excesso, já que ela também deve ser invocada quando se fala no dever de proteção por parte do Estado, a exigir-lhe uma atuação positiva a fim de proteger os seres humanos também quanto a agressões provenientes de terceiros contra os seus direitos fundamentais. São os direitos prestacionais sobre os quais fala ALEXY, que seriam "aquellas medidas estatales (...) que son indispensables para la protección del ámbito de libertad assegurado por el derecho fundamental' (ALEXY, 2007).

Tais direitos a uma ação positiva do Estado podem trasvestir-se de um caráter fático ou de um caráter normativo - "derechos prestacionales en sentido estricto" e "derechos prestacionales en sentido amplio" (ALEXY, 2007), respectivamente. Essa é, então, a faceta do princípio da proporcionalidade 
Infiltração de agentes e a nova lei de enfrentamento às organizações criminosas

chamada proibição de insuficiência no campo jurídico-penal e, por conseguinte, na esfera da política criminal.

É possível dizer, dessa forma, que dos direitos fundamentais extraemse os mandamentos de proteção, que exigem do Estado uma verdadeira atuação em prol da proteção das liberdades dos cidadãos. Essa conclusão também decorre do princípio do Estado de Direito, na medida em que o Estado é o tradicional detentor do monopólio, tanto da aplicação da força, quanto no âmbito da solução dos litígios entre os particulares, que (salvo em hipóteses excepcionais, como o da legítima defesa), não podem valer-se da força para impedir e, especialmente, corrigir agressões oriundas de outros particulares.

Sob essa perspectiva, SARLET afirma que:

Os direitos fundamentais (mesmo os clássicos direitos de liberdade) devem ter sua eficácia valorada não só sob um ângulo individualista, isto é, com base no ponto de vista da pessoa individual e sua posição perante o Estado, mas também sob o ponto de vista da sociedade, da comunidade na sua totalidade, já que se cuidam de valores e fins que esta deve respeitar e concretizar. Com base nesta premissa, a doutrina alienigena chegou à conclusão de que a perspectiva objetiva dos direitos fundamentais constitui função axiologicamente vinculada, demonstrando que o exercicio dos direitos subjetivos individuais está condicionado, de certa forma, ao seu reconhecimento pela comunidade na qual se encontra inserido e da qual não pode ser dissociado, podendo falar-se, neste contexto, de uma responsabilidade comunitária dos individuos. É neste sentido que se justifica a afirmação de que a perspectiva objetiva dos direitos fundamentais não só legitima restriçôes aos direitos subjetivos individuais com base no interesse comunitário prevalente, mas também e de certa forma, que contribui para a limitação do conteúdo e do alcance dos direitos fundamentais, ainda que deva sempre ficar preservado o núcleo essencial destes" (SARLET, 2005).

Para que o Estado não frustre o seu dever de proteção, atuando de modo insuficiente, devem ser discutidas as medidas que podem mostrar-se mais eficientes para a proteção dos seres humanos, tanto em sua perspectiva individual quanto coletiva, contra as constantes ameaças aos seus direitos, especialmente, naquilo que nos interessa, o direito à segurança.

Para tanto, é preciso pensar numa ponderação de valores que possa legitimar a eficiente repressão, através dos sistema jurídico penal, a essas fon- 
tes de ameaça. Essa ponderação deverá ter em conta as liberdades individuais de um lado e a necessidade de conferir maior eficiência à persecução penal, especialmente frente à criminalidade organizada.

BALTAZAR JÚNIOR discorre que:

Embora reconhecida, prima facie, a preponderância do direito individual, recaindo a carga da argumentação sobre quem pretende sua restrição, tenho que tanto o direito à segurança, a ser alcançado mediante uma proteção penal eficiente, quanto os direitos fundamentais do acusado devem ser preservados, sendo a preponderância afirmada, ao final, por meio da ponderação" (2010, p. 209).

Defende-se, com isso, uma proteção aos direitos pessoais e coletivos, previstos no art. $5^{\circ}$ da Constituição Federal, não só por meio da limitação ao poderio estatal em face dos acusados, mas também através da aplicação eficaz do Direito Penal e Processual Penal, "fundamentado na normatividade constitucional e convencional, assecuratório dos direitos e das liberdades fundamentais" (GIACOMOLLI, 2014, p. 22), inclusive mediante uma eficiente persecução penal.

É bom que se diga que as políticas criminais mais eficientes para o enfrentamento a esse novo modelo de criminalidade organizada e transnacional não se restringem às ferramentas repressivas. A bem da verdade, o Estado deve preocupar-se, antes de mais nada, com as políticas destinadas à prevenção da ocorrência de crimes dessa vulta, assim como dos delitos ditos tradicionais.

Foi enfatizado anteriormente que uma das principais "armas" utilizadas pelas organizações criminosas, seja para potencializar seus lucros, seja para a blindagem de seus membros e empresas, é a infiltração de seus agentes na estrutura do Estado. Sem acesso às estruturas lícitas da sociedade, sejam estatais ou não estatais, o crime organizado não encontraria o ambiente propício para crescer, eis que se alimenta, também, de produtos e serviços legais na sua atuação.

Quanto a esse aspecto, GUEDES VALENTE afirma:

O crime organizado, como já disséramos, necessita da rede estabelecida legalmente para se espalhar e se enraizar quer de forma directa quer de forma paralela e utiliza as malhas de restrição legal e de lacunas legais para se trincheirar e ganhar forma em primeira mão ilícita e em segunda mão lícita" (2009, p. 161) 
Infiltração de agentes e a nova lei de enfrentamento às organizações criminosas

A fim de evitar a disseminação, o fortalecimento e o enriquecimento das organizações criminosas, é preciso que o Estado, paralelamente à preocupação com a eficiente repressão, concentre esforços em estruturar as instituições públicas com barreiras que restrinjam a infiltração de criminosos.

Nesse ponto destaco, mais uma vez, as palavras de GUEDES VALENTE:

A prevenção deste perigo dever-se-ia, prima facie, centrar numa atividade jurídico-administrativa policial em áreas como o controle e a fiscalização das atividades licenciadas pelo Estado - como os sectores da indústria, da imigração, da importação e exportação de bens (de consumo ou matérias primas), da construção civil e imobililário, da exploração de estabelecimentos de restauração e hotelaria, da importação e exportação de armas, da importação e exportação de fármacos, da importação e exportação de automóveis, da emissão de documentos pessoais (passaporte, carta de condução, número fiscal), da banca (através do banco central de cada Estado-membro), do desporto, da internet etc. Caso existisse um sério e real controlo e fiscalização destas actividades lícitas - pois, o mundo do crime estrutura e organizado utiliza as estruturas organizadas legalmente para proliferação dos seus intentos - e se actuasse no plano administrativo preventivo e sancionatório, prevenia-se e evitava-se o recurso excessivo ao direito penal material e processual" (2009, pp. 160-161).

A todas essas atividades lícitas sujeitas à fiscalização estatal adicionamos o sistema financeiro e de mercado de valores, onde efetivamente transita a maior parte do dinheiro obtido a partir da exploração dos mercados ilícitos ou a partir de quaisquer outras atividades desenvolvidas pelas organizações criminosas. O sistema financeiro e as bolsas de valores merecem, portanto, um olhar mais cuidadoso e atento do Estado em sua regulação.

Não obstante reconhecida a importância das ações de cunho preventivo que devem ser implementadas pelo Estado na sua luta contra o crime organizado, o presente trabalho centra sua análise nos mecanismos de repressão, em especial, na técnica especial de investigação de infiltração de agentes, motivo pelo qual restringiremos o nosso exame à referida técnica, sem deixar de comentar outros mecanismos correlatos.

Sob esse enfoque, entendemos ser necessário o aprimoramento dos atores da persecução penal e das ferramentas estatais destinadas à repressão penal. Nesse universo, destacamos os meios ocultos de investigação, tais como 
escutas telefônicas, gravações ambientais e agentes infiltrados, cujas vantagens para a perseguição às formas mais graves de criminalidade são óbvias.

É relevante repisar que os instrumentos que se pretendem ver aprimorados não se destinam à repressão de crimes segundo a concepção do Direito Penal clássico, que são essencialmente unipessoais e voltados contra um ou poucos indivíduos. O que se almeja, neste estudo, é defender um melhor e mais eficiente arcabouço legal destinado a prevenir e reprimir, com melhores resultados, a nova criminalidade organizada, "que, para além de mobilizarem meios sem precedentes e exibirem poder que ombreia com o de muitos Estados, em geral, adoptam formas de organização e de interação que as tornam imunes à intromissão e devassa das instâncias de controlo" (ANDRADE M. C., 2009). Esse forte poderio econômico concede-lhes maior capacidade de ocultar vestígios e provas do que a criminalidade tradicional, dá-lhes potencial para atingir número indistinto de indivíduos, além de permitir-lhes, em casos mais graves, desestabilizar o Estado Democrático.

A esse respeito, nos diz PEREIRA que:

En esencia, como resulta inviable afrontar la represión del crimen organizado mediante el recurso a las vías legales arbitradas para la delincuencia tradicional, ha tenido lugar una especialización de la norma procesal penal contra la delincuencia asociativa. Dicho en otras palabras, se ha llegado a la conclusión de que la lucha estaría quedando desigual en términos de combate al crimen organizado, especialmente en razón de que en la gran mayoría de las veces, se intenta luchar contra un oponente imaginario, por veces desconocido respecto a su estructura y logística, y además, de lo cual no se tiene un completo conocimiento con relación a los aspectos internos de su modus operandi (2012, p. 346).

No cenário que estamos a tratar, em que se discute meios de melhor municiar, sob o amparo do ordenamento jurídico, os órgãos estatais responsáveis pela repressão criminal, desde a fase processual-investigatória, até a fase da ação penal, consideramos que a edição da Lei no $12.850 / 2013$ coroou os avanços legislativos que foram, ao longo dos anos, sendo adotados no país para o enfretamento às organizações criminosas, desde edição da Lei dos Crimes Hediondos, passando pela revogada Lei do Crime Organizado, pela Lei de Lavagem de Dinheiro, pela Lei de Drogas, pela Lei de Proteção a Réus e Testemunhas, além de convenções e tratados internacionais, os quais já previam e disciplinavam, em parte, as técnicas especiais de investigação. 
Infiltração de agentes e a nova lei de enfrentamento às organizações criminosas

Contudo, no que tange à técnica da infiltração de agentes, consideramos que a nova lei apresenta uma limitação incompatível com os novos desafios impostos por esse tipo de criminalidade. Conforme será exposto a seguir, a práxis da Polícia Federal permitiu demonstrar que não só a infiltração de agentes de polícia tende a ser uma importante técnica de investigação, como também a infiltração de terceiros, principalmente quando são egressos das organizações criminosas e passaram à condição de colaboradores da justiça.

\section{A Lei No 12.850/2013 E A Infiltração de Agentes}

Consoante já exposto supra, vimos que o enfrentamento ao crime organizado exige dos Estados um melhoramento na qualidade de suas investigações, seja otimizando e aprimorando as técnicas mais tradicionais (como obtenção de documentos e toda sorte de vestígios de crimes, com respeito à cadeia de custódia, colheita de depoimentos e interrogatórios com respeito às garantias constitucionais dos investigados e acusados em geral etc.), seja valendo-se de meios ou técnicas especiais de investigação, dentre os quais os meios ocultos, mais especializados e tecnológicos, de modo a adequar-se às novas demandas, nacionais e internacionais, de combate à criminalidade.

Em resposta a essas demandas, o legislador brasileiro editou a Lei $\mathrm{n}^{\circ}$ $12.850 / 2013$, que estabelece, dentre os meios investigatórios regulamentados para apurações relacionadas ao crime organizado, a técnica da infiltração de agentes. Esse meio de investigação e obtenção de provas já estava previsto na Lei $n^{\circ} 9.034 / 95$, cujo dispositivo foi acrescentado somente seis anos após a promulgação da referida Lei ${ }^{7}$. Contudo, esse diploma não cuidava de disciplinar suficientemente o procedimento da infiltração de agentes, deixando a sua aplicação prática muito mais aberta e passível de excessos.

Já a nova lei de combate ao crime organizado, para além de ratificar a infiltração de agentes como meio investigativo, dedicou toda uma seção para a disciplina do procedimento a ser seguido quando da sua utilização. Em seu artigo 10, o diploma legal em estudo prevê: "A infiltração de agentes de polícia em tarefas de investigação, representada pelo delegado de polícia ou requerida pelo Ministério Público, após manifestação técnica do

7 A Lei n ${ }^{\circ}$ 10.217/2001 previu a possibilidade de "infiltração por agentes de polícia ou de inteligência, em tarefas de investigação, constituída pelos órgãos especializados pertinentes, mediante circunstanciada autorização judicial" 
delegado de polícia, quando solicitada no curso de inquérito policial, será precedida de circunstanciada, motivada e sigilosa autorização judicial, que estabelecerá seus limites".

O agente infiltrado seria aquele que, mediante a prévia e indispensável autorização judicial, e sob o controle do órgão policial, insere-se no âmago de uma organização criminosa sob falsa identidade, com o fim de conquistar a confiança de seus membros, com eles conviver, até mesmo em seu meio familiar, e com isso obter informaçóes, indícios e provas das atividades criminosas desenvolvidas pelos integrantes daquela organização, destinando-se seu resultado à instrução processual penal (VALENTE, 2016, pp. 498-499).

Interessante notar, conforme esclarece PEREIRA, que a técnica da infiltração de agentes é uma das mais antigas para a apuração de crimes. Sobre isso o citado autor escreve:

Este es un punto muy importante a tener en cuenta, en la medida en que se puede afirmar con seguridad que uno de los métodos más antiguos de control de la criminalidad consiste en que el agente investigador realice una búsqueda de datos e informaciones ocultando su pertenencia al poder público, con lo que consigue el acceso a ambientes sociales y a personas que tendria vedado si no actuara de forma subrepticia (2012, p. 346).

Pois bem, da nova disciplina legal da técnica de infiltração de agentes, importa, antes de tudo, destacar que o legislador normatizou os princípios da indispensabilidade e da subsidiariedade (VALENTE, 2016, pp. 517-518) da medida, ao prever que a infiltração somente será admitida quando houver indícios do cometimento de infração penal de que trata o art. $1^{\circ} \mathrm{e}$ se a prova não puder ser produzida por outros meios disponíveis (art. 10, $\$ 2^{\circ}$ ). Com isso, somente em casos de justificada e motivada necessidade, quando os investigadores não tiverem acesso a outros modos de produzir provas em face daquela organização, é que poderá ser admitido uso a esse recurso investigativo.

Trata-se de um meio excepcional de obtenção de prova, que deve ser utilizado apenas, e tão-somente, quando verificados os pressupostos contidos na Lei ${ }^{\circ}$ 12.850/2013 e absoluta necessidade à obtenção de provas de crimes cometidos por organizações criminosas, pois "éum meio de obtenção de prova que colide com direitos fundamentais pessoais - como a reserva da vida privada e familiar (...)" (VALENTE, 2016, p. 495). Em outras palavras, esse recurso, por extremo que é, deve ser aplicado em investigações apenas quando outros 
Infiltração de agentes e a nova lei de enfrentamento às organizações criminosas

meios não se mostrarem eficazes na busca de provas que ajudem a clarificar os fatos em investigação.

É um recurso considerado extremo justamente pela sua forte carga de restrição aos direitos fundamentais da pessoa investigada, pois implica, primordialmente, na invasão à sua intimidade e à sua privacidade. Diante disso, o recurso a esse meio investigativo deverá estar, necessariamente, relacionado com a prática de delitos marcados por extrema gravidade e, quiçá, pelo emprego de sofisticação e violência (PEREIRA, 2012).

Por essa razão, o uso indiscriminado desse recurso investigativo, fora das hipóteses legalmente autorizadas, poderá gerar a invalidade da provas colacionadas e a necessidade de sua extração do processo penal. A esse respeito, GIACOMOLLI afirma:

Assim, inválida é a aquisição de uma prova inadmissivel, na medida em que os defeitos originais contaminam os atos subsequentes, que se situam dentro de um parâmetro de dependência. Inválida também é a aquisição que contrarie a dignidade humana (art. $1^{\circ}$, III, CF), a liberdade moral e as garantias processuais, constitucionais e infraconstitucionais, ou seja, o devido processo (2014, p. 160).

Demais disso, com o novo regramento legal foi consagrado o princípio da adequabilidade na execução da infiltração, segundo o qual, além de indispensável, a técnica da infiltração de agentes deverá ser tida como adequada para a obtenção das provas de autoria e materialidade delitiva que se está a apurar. Afigura-se imperiosa a demonstração da utilidade da medida para os fins do processo penal, sob pena de não poder ser autorizada a infiltração de agentes.

O princípio da proporcionalidade também obteve especial atenção na Lei $n^{\circ} 12.850 / 2013$, eis que foi prevista, expressamente, a possibilidade de o agente infiltrado responder pelos excessos de sua conduta, quando a sua atuação não guardar a devida proporcionalidade com a finalidade da investigação.

Sendo assim, na condição de infiltrado judicialmente autorizado, não pode o agente proceder da forma como bem entender, sem limites de ação, sem observância aos direitos fundamentais e à legalidade. Sua ação deverá estar estritamente pautada pelos limites fixados no interesse da investigação e, sobretudo, nos princípios da lealdade ou fair trail (VALENTE, 2016, p. 508), da proporcionalidade e do respeito à dignidade humana. 
Como dito, toda a sua atuação deverá guardar conformidade com os estritos interesses da investigação em curso, não sendo admissível ao agente, com esse intento, instigar, fomentar ou induzir o investigado a praticar crimes que já não tenha iniciado, sob pena de invalidade das provas coligidas. É fundamental, portanto, distinguir as figuras do agente infiltrado e do agente provocador.

A ação do agente infiltrado, para ser tida por legítima e juridicamente protegida, não pode ser o motivo desencadeador da prática do crime. Trata-se, neste último caso, da ação do agente provocador, que é aquele que, com sua ação, induz ou instiga outros a praticar crimes, como por exemplo, aquele que age como comprador de drogas, de armas, ou mesmo aquele que se dispõe a fornecer serviços ilícitos. Essa forma de agir fere o princípio democrático, que "impóe que ao cidadão seja dada a liberdade de escolb a dos seus actos" (VALENTE, 2016, p. 507), além de violar a dignidade da pessoa humana.

No direito brasileiro, a conduta do agente provocador motivaria a situação do "crime preparado", considerada atípica para o seu autor, no caso, o investigado da ação de infiltração. É que, nessa hipótese, é o Estado, por seu representante, que cria a conduta criminosa, resultando o delito da atividade do agente infiltrado. Aplica-se, na espécie, o art. 17 do Código penal (crime impossível) e a Súmula no 145 do STF (Não há crime, quando a preparação do flagrante pela polícia torna impossível a sua consumação).

Sendo assim, para ter sua ação considerada legítima, o agente infiltrado deve restringir-se a ganhar a confiança do(s) investigado(s) a fim de melhor observar suas ações, colher informações e provas de sua atividade criminosa. Não poderá, portanto, ser agente instigador ou mesmo o autor mediato do ato criminoso.

Muito embora não possa instigar ou provocar a prática do ato ilícito, o agente infiltrado, autorizado judicialmente e sob o controle da Polícia Judiciária, poderá auxiliar o investigado na prática de crimes ou, em última análise, até praticar por si mesmo atos executórios de delitos, desde que lhe seja inexigível conduta diversa. Essa é a leitura que se faz do artigo 13, parágrafo único, da Lei no 12.850/2013 ("Não é punível, no âmbito da infiltração, a prática de crime pelo agente infiltrado no curso da investigação, quando inexigível conduta diversa"). 
Nesse ponto, é importante frisar que a nova Lei trouxe as linhas básicas a suprir relevante lacuna normativa verificada no diploma anterior ${ }^{8}$. Com efeito, a Lei no 9.034/95 nada dizia a respeito da responsabilidade do agente infiltrado no que tange à prática de crimes no contexto da infiltração. É sabido que em certos modelos de organizações criminosas (a exemplo daquelas com características mafiosas), seus integrantes podem demandar, para aceitação de um novo membro, provas de lealdade, que muitas vezes resvalam no cometimento de crimes.

Sob a regência da antiga Lei, o agente infiltrado parecia encontrar-se desamparado de excludentes de ilicitude que pudessem ser aplicadas automaticamente à sua ação. Por não existir qualquer referência positiva para as excludentes de tipicidade, ilicitude e culpabilidade diretamente vinculadas às ações do agente infiltrado, sua atuação no seio da organização criminosa ficava, apenas, sob o amparo dos limites da autorização judicial no caso concreto, o que gerava imensa insegurança jurídica e dificuldades práticas para implementar essa técnica investigativa.

$\mathrm{Na}$ atualidade, a Lei $\mathrm{n}^{\circ} 12.850 / 2013$ prevê expressamente que não é punível, no âmbito da infiltração, a conduta do agente que pratica crimes, desde que comprovada a inexigibilidade de conduta diversa. Por óbvio, não se aplica tal excludente de ilicitude para o agente que provoca o crime.

Para além da garantia de que seus atos ilícitos praticados no curso da ação de infiltração e nos estritos limites da exigibilidade não serão puníveis, a Lei de combate às organizações criminosas também trouxe outras garantias aos agentes infiltrados, visando proteger a sua segurança e identidade.

Nesse sentido, o legislador garantiu a possibilidade do agente recusar sua participação como infiltrado no grupo, ou mesmo a cessação imediata da medida invasiva quando houver risco a sua integridade física e/ou psicológica. Garante-se-lhe, igualmente, o direito a ter sua identidade alterada e o ingresso a programas de proteção a testemunhas. Tem direito, também, a ter seu nome, sua qualificação, sua imagem, sua voz e demais informações

8 Interessante notar que no direito português a técnica de infiltração de agentes é disciplinada pela Lei n. 101/2001, de 25 de abril, a qual já tratava da questão da responsabilidade penal do agente infiltrado pelas condutas ilícitas que cometer durante sua atuação. Quanto a isso, a lei portuguesa estabeleceu, em seu artigo $6^{\circ}$, que "Não é punível a conduta do agente encoberto que, no âmbito de uma acção encoberta, consubstancie a prática de actos preparatórios ou de execução de uma infracção em qualquer forma de comparticipação diversa da instigação e da autoria mediata, sempre que guarde a devida proporcionalidade com a finalidade da mesma”. 
pessoais preservadas durante a investigação e o processo criminal, salvo se houver decisão judicial em contrário, além de lhe ser assegurado o direito de não ter sua identidade revelada, nem ser fotografado ou filmado pelos meios de comunicação, sem sua prévia autorização por escrito .

Há que se reconhecer, por todo o exposto, que a Lei no 12.850/2013 representa, de um modo geral, um largo avanço no que respeita à regulamentação da técnica de infiltração de agentes em organizações criminosas, pois disciplinou aquilo que a revogada Lei no 9.034/95 havia deixado reticente. Não obstante, consideramos que o legislador restringiu em demasia e limitou muito o espaço de ação quando excluiu a possibilidade de terceiros não-policiais atuarem como infiltrados sob o comando da polícia judiciária, conforme exporemos a seguir.

O já transcrito artigo 10 da nova Lei de Combate às Organizações Criminosas estabelece que a infiltração será realizada apenas por policiais, afastando a hipótese de agentes de inteligência (como antes previa a Lei $\mathrm{n}^{\circ}$ 9.034/95) ou terceiros, integrantes de outros órgãos estatais ou mesmo civis sem qualquer vinculação com o governo, atuarem como infiltrados com autorização judicial e sob o amparo da polícia judiciária.

Considero que, com essa restrição, a lei limitou a eficácia da aplicação do meio de investigação em estudo, por impossibilitar a utilização de pessoas que, sendo muitas vezes originárias dos grupos ou organizações criminosas, poderiam com maior probabilidade de sucesso colaborar com os órgãos de investigação criminal.

Com efeito, a práxis em investigações realizadas pela Polícia Federal brasileira demonstra que a utilização de terceiros infiltrados pode resultar em significativa colheita de provas em face de membros da organização criminosa sob investigação, como a casuística demonstrou em recentes investigações, em especial naquelas destinadas a desarticular associações de narcotraficantes, em que atuaram, como infiltrados, civis e policiais de outros países.

Há situações em que integrantes da própria organização investigada predispõem-se a colaborar com a justiça, em troca de abrandamento de penas ou mesmo de perdão judicial, hipótese em que haveria uma aplicação conjunta da disciplina legal destinada à colaboração premiada. Essa técnica investigativa está disciplinada nos artigos $4^{\circ}$ a $7^{\circ}$ da Lei no $12.850 / 2013$ e pode se mostrar um importante aliado na repressão a organizações criminosas. 
É verdade que esse instrumento também pode mostrar-se nocivo quando passa a ser usado como meio de coagir investigados a delatarem "comparsas" ou mesmo rivais no crime, mas não se pode excluir sua utilidade e importância como ferramenta investigativa quando utilizada dentro dos limites legais e constitucionais, sobretudo quando não se perde de vista os princípios ligados às liberdades fundamentais dos indivíduos (inclusive aquela relativa ao direito ao silêncio) e à dignidade da pessoa humana. Mas não sendo objeto desde trabalho, não nos alongaremos na análise da colaboração premiada como técnica de investigação.

Adentramos na questão da colaboração premiada apenas para ressaltar que esse meio de apuração de crimes pode ser usado para dar início a uma ação de infiltração, quando um integrante da organização criminosa investigada, já sob a tutela judiciária e controle operativo policial, poderá a ela regressar com o intuito de auxiliar o órgão investigativo na apuração, coletando indícios e provas dos delitos perpetrados pelos demais membros.

Enfatizamos linhas acima sobre as imensas dificuldades que circundam a averiguação e efetiva colheita de provas para enfrentar a moderna criminalidade organizada. Dissemos que ela tem, em regra, caráter transnacional, tecnológico, além de guardar um poderio econômico relevante e suficiente para ocultar provas e vestígios, transformando os crimes que pratica em atos quase imperceptíveis. Para além disso, é também capaz de se infiltrar nas "entranhas" do Estado, seja para corromper funcionários, seja para inserir membros próprios nas estruturas estatais, tudo com o intento de assegurar a realização de seus objetivos ilícitos e a impunidade.

Sendo assim, considero imprescindível que o Estado robusteça seus meios de investigação, sem ultrapassar os limites constitucionais e legalmente aceitáveis no Estado Democrático de Direito, mas garantindo-lhe a oportunidade de obter resultados mais eficazes na "luta" contra a criminalidade organizada.

Sobre a possibilidade de o terceiro ser infiltrado em ações coordenadas pela Polícia e autorizadas judicialmente, destaco, a título de exemplo, que a legislação de vários países, dentre as quais a portuguesa, permite a utilização de elementos não policiais em açôes desse jaez, sob o controle da Polícia Judiciária.

Em Portugal, a Lei no 101/2001 tratou do tema e alargou o âmbito de possível atuação do agente infiltrado, prevendo, além de mais tipologias 
para o emprego da técnica, a possibilidade de utilização do terceiro. Esse alargamento, esclareça-se, decorreu da necessidade de adequação da legislação portuguesa às demandas da União Europeia para o mútuo auxílio judiciário em matéria penal entre os Estados-Membros, inclusive para o enfrentamento às organizações criminosas (VALENTE, 2016, p. 496).

Teses contrárias à autorização para que o terceiro seja utilizado como agente infiltrado defendem que restaria duvidosa a legitimidade ético-jurídica da medida, diante da possibilidade de o terceiro atuante nesta condição ter interesses diretos quanto ao crime a investigar, "o que lhe proporciona um melhor controlo das operaçôes da Polícia e, consequentemente, da sua atividade ilícita" (VALENTE, 2016, p. 515).

Outrossim, aqueles que se opõem a essa ampliação do âmbito subjetivo de realização da infiltração afirmam que o particular não teria condiçôes psicológicas para suportar o mundo do crime, nem conhecimentos práticos suficiente para lidar com criminosos. De outra banda, argumentase que os particulares seriam mais facilmente corrompíveis no ambiente criminoso (PEREIRA, 2012).

Embora reconheçamos os maiores desafios inerentes a uma operação de infiltração com agentes não-policiais, cremos ser possível alcançar bons resultados com o recurso a esse meio de investigação e manter o controle da ação do infiltrado, conformando a sua atuação àquilo que realmente interessa à investigação criminal e coibindo os excessos que possa, eventualmente, vir a cometer.

Infiltrados que sejam egressos do mundo do crime e com fortes interesses em ver sua situação perante a Justiça abrandada (no caso de serem favorecidos pela aplicação dos benefícios da colaboração premiada) não vivenciariam as dificuldades de ordem psicológica e prática acima apontadas. Por outro lado, temos que a possibilidade de se deixarem corromper é algo que, infelizmente, assombra tanto policiais quanto particulares, não sendo este, a nosso ver, motivo suficiente e bastante para limitar legalmente o recurso à técnica de infiltração de terceiros, especialmente associada à colaboração premiada. 
Infiltração de agentes e a nova lei de enfrentamento às organizações criminosas

\section{Consideraçốes Finais}

De tudo quanto exposto, consideramos estar patente a necessidade de o Estado se aprimorar juridicamente para o enfrentamento à criminalidade organizada. Esse aprimoramento se inicia desde o incremento de políticas criminais preventivas que visem abafar ou dificultar o fortalecimento, enraizamento e enriquecimento das organizações criminosas nos mercados ilícitos ou lícitos que elas exploram, mas também passa por uma revisão na sua legislação repressora, com destaque aqui para a Lei no $12.850 / 2013$, que trata dos procedimentos investigatórios destinados ao "combate" ao crime organizado.

Nesse aspecto, entendemos que a Lei atual avançou sobremaneira quando, primeiramente, definiu o conceito e tipificou o crime de organização criminosa, ultrapassando a antiga celeuma que girava em torno do enquadramento típico dessa espécie de criminalidade e, em segundo, quando disciplinou mais detalhadamente os recursos a que podem aceder os órgãos encarregados da repressão, sobretudo a polícia judiciária, nas apurações que visem desmantelar grupos estruturados, integrados por 4 (quatro) ou mais pessoas, caracterizados pela divisão de tarefas, destinados à prática de crimes puníveis com penas máximas superiores a 4 (quatro) anos, ou que tenha caráter transacional.

Contudo, a par dos avanços reconhecidos, entendemos, também, que a Lei no 12.850/2013 não acompanhou as demandas reais relacionadas à repressão das organizaçóes criminosas, pois deixou de prever a possibilidade de o terceiro não-policial ser autorizado a participar de operações de infiltração.

A fim de melhor aparelhar o Estado na sua "luta" contra as organizações criminosas, possibilitando que os órgãos incumbidos da prevenção e repressão ao crime organizado alcancem resultados mais eficazes na missão de frear a disseminação e o fortalecimento econômico dessas organizações, é imperioso, além de investir na melhoria de recursos humanos e materiais das Polícias e demais atores da persecução penal, enriquecer a legislação com mecanismos de investigação que possam aclarar o modus operandi dessas redes criminosas, identificar seus principais líderes e membros e amealhar provas para a aplicação da lei penal, num Processo Penal justo, de raiz constitucional e caráter humanitário (GIACOMOLLI, 2014) e amparado pelo contraditório e ampla defesa. 
A técnica especial de infiltração de agentes é um desses mecanismos que podem contribuir para a repressão ao crime organizado e deve, portanto, ter seu âmbito de aplicação subjetiva ampliado, a fim de permitir que agentes não-policiais possam ser utilizados como infiltrados nas organizações criminosas. Com o necessário controle por parte da polícia judiciária, e com a observância da proporcionalidade, razoabilidade, indispensabilidade, subsidiariedade e adequação em relação aos fins almejados na investigação, a execução da técnica de infiltração de terceiros pode ser um excelente recurso para o combate ao crime organizado.

Considerando a opção do legislador ao editar a Lei no 12.850/2013 com a restrição já explanada, propomos a rediscussão da matéria a fim de fomentar a alteração da Lei em questão visando à ampliação do âmbito subjetivo de utilização da técnica especial de investigação de infiltração de agentes, objetivando possibilitar que o terceiro não-policial também possa ser autorizado a infiltrar-se em organizações criminosas.

O legislador precisa se conscientizar acerca dos grandes desafios impostos aos órgãos incumbidos da investigação e da repressão penal ao crime organizado, bem como das necessidades processuais que daí decorrem. A instrumentalização do Estado com ferramentas que possam se mostrar úteis e efetivas nesse enfrentamento é algo essencial e urgente no cenário mundial, em que o crime organizado se prolifera e se torna cada vez mais robusto frente ao Estado.

Concluímos este estudo com as palavras de GUEDES VALENTE, que nos alerta para a necessidade de melhor aparelhamento do Estado para prevenir e reprimir a criminalidade organizada:

A busca por mecanismos capazes de prevenir e investigar a criminalidade mais grave - altamente organizada, complexa, violenta, transnacional, internacional - e que mais preocupa e fere o normal desenvolvimento do Homem impele o legislador a decidir ampliar o âmbito das acções encobertas, vulgo agente infiltrado, subordinando o regime estabelecido aos principios norteadores da justiça, ajustando a lei ao tempo dos nossos dias e dando à sociedade a segurança jurídica no sentido de legalizar um meio de investigação excepcional (...)" (2016, p. 492).

uficiência, 2005). 


\title{
Undercovered Agents and the New Anti- Organized Crimes LaW
}

\begin{abstract}
Facing criminal organizations is becoming increasingly challenging because of the high economic power, transnational and technological character of such organizations. These organized groups dedicate themselves to the practice of the most diverse crimes, such as traffic in narcotics, arms, people, smuggling, white-collar crime and money laundering, among others. It is also seen the great capacity of organized crime to infiltrate criminals in the Government in order, through corruption, to ensure that its illicit goals are achieved and that its members are not punished by justice. Faced with the immense difficulties of confrontation, it is important that the State improves its mechanisms of prevention and repression of organized crime, so as to enable a safer life in society. In this attempt, Law No. 12,850 / 2013 was issued, which regulated several special investigative techniques, applicable to crimes committed by criminal organizations, among which the undercovered agents. However, even though the new law had advanced in the best discipline of the procedure to implement the technique in question, it was timid to authorize only the use of the police as an undercovered agent into criminal organizations. In conclusion, it is proposed to re-discuss the topic in order to encourage legislative change to broaden the subjective spectrum of use of this important special investigative technique.
\end{abstract}

Keywords: organized crime; criminal organizations; transnational crime; repression; undercovered agents.

\section{Infiltración de Agentes y la Nueva Ley de Enfrentamiento a las Organizaciones Criminosas}




\section{RESUMEN}

El enfrentamiento a las organizaciones criminales se vuelve cada vez más desafiante, debido al alto poder económico y las características transnacionales y tecnológicas que revisten dichas organizaciones. Estos grupos organizados se dedican a la práctica de los más diversos crímenes, como tráfico de estupefacientes, de armas, de personas, contrabando, además de crímenes del cuello blanco y lavado de dinero, entre otros. Se ve, además, la gran capacidad de las organizaciones criminales infiltrarse en el Estado para, mediante corrupción, garantizar que sus objetivos ilícitos sean alcanzados y que sus miembros no sean punidos por la Justicia. Ante las inmensas dificultades de enfrentamiento, es importante que el Estado mejore sus mecanismos de prevención y represión al crimen organizado, para hacer viable una vida en sociedad con más seguridad. En ese intento, fue editada la Ley no 12.850 / 2013, la cual disciplinó diversas técnicas especiales de investigación, aplicables a los crímenes cometidos por organizaciones criminales, entre las cuales la infiltración de agentes. Sin embargo, a pesar de que el nuevo diploma legal ha avanzado en la mejor disciplina del procedimiento para implementar la técnica en cuestión, se mostró tímida al autorizar, sólo, la utilización del policía como agente infiltrado en organizaciones criminales. Se propone, en conclusión, la rediscusión del tema a fin de fomentar la alteración legislativa para ampliar el espectro subjetivo de uso de esta importante técnica especial de investigación.

Palabras Clave: organizaciones criminales; Transnacionalidad; La represión; Ley nº 12.850 / 2013; Infiltración de agentes;

\section{REFERÊNCIAS}

ALEXY, R. (2015, 2a edição, 4a tiragem, tradução Virgílio Afonso da Silva). Teoria dos Direitos Fundamentais. São Paulo: Malheiros Editores.

ANDRADE, M. C. (1992). Sobre as Proibições de Prova em Processo Penal. Coimbra: Coimbra Editora.

FELDENS, L. (2012). Direitos Fundamentais e Direito Penal - A

Constituição Penal. Porto Alegre: Livraria do Advogado Editora.

GODOY, L. R. (2011). Crime Organizado e seu Tratamento Jurídico Penal. São Paulo: Elsevier.

JÚNIOR, J. P. (2010). Crime Organizado e Proibição de Insuficiência. Porto Alegre: Livraria do Advogado.

PEREIRA, F. C. (2012). Agente Encubierto y Proceso Penal Garantista: Límites y Desafíos. Córdoba: Lerner Editora. 